
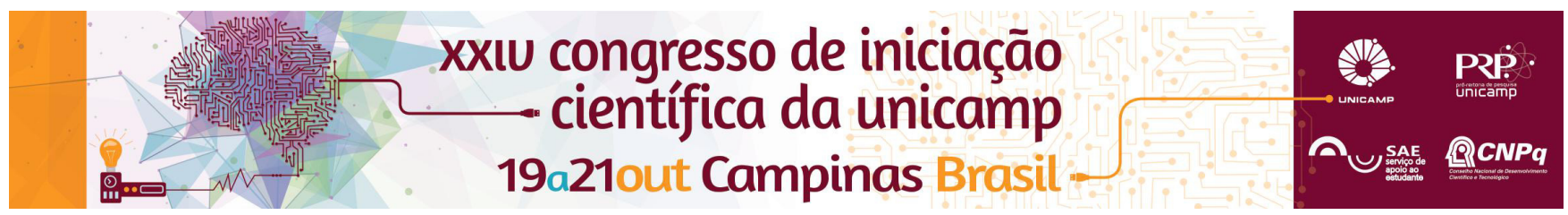

\title{
O desempenho de atletas nas modalidades esportivas constituintes da corrida de aventura em provas de 35 a $50-\mathrm{km}$.
}

\section{Bruna S. Silva*, Pedro de S. Rosa, Taisa Belli. Ciências do Esporte - Faculdade de Ciências Aplicadas-UNICAMP}

\section{Resumo}

O presente estudo teve como objetivo analisar a possível relação do desempenho de atletas nas modalidades de mountain bike e trekking com o seu desempenho final durante provas de corrida de aventura. Para tanto, 24 atletas participantes de etapas do Circuito Haka Race de Corrida de Aventura/2105 foram voluntários nesse estudo. Observamos que a velocidade de prova das duplas foi correlacionada significativamente $(P<0,05)$ com a velocidade do primeiro trecho de trekking $(R=0,80)$ e do último trecho de mountain bike $(R=0,72)$ na $2^{a}$. etapa do Circuito, enquanto que na $4^{\mathrm{a}}$ etapa foi associada significativamente $(\mathrm{P}<0,05) \mathrm{com}$ a velocidade do percurso de water trekking com trekking $(\mathrm{R}=0,95)$.

Palavras-chave: corrida de aventura, mountain bike, trekking.

\section{Introdução}

A corrida de aventura (CA) é um esporte constituído a partir da união de modalidades esportivas, como mountain bike, canoagem, trekking, orientação, entre outros, realizadas em intenso contato com diferentes ambientes da natureza. As modalidades mais presentes na CA, tendo em vista um maior tempo de duração, são trekking e o mountain bike (JUNIOR, et al. 2008). Os estudos são escassos sobre a contribuição relativa de cada uma dessas modalidades para o sucesso em uma prova de CA e ainda pouco explorado pela literatura científica. Já no triathlon, esporte com características similares a CA, essa temática vem sendo muito estudada, dada sua importância para o desempenho dos atletas, mostrando que os tempos parciais de ciclismo e corrida estão correlacionados com o tempo total de prova (FIGUEIREDO et al., 2016). Dessa maneira, o presente estudo teve como objetivo analisar a possível relação do desempenho de atletas na modalidade de mountain bike e trekking com o seu desempenho final durante duas provas de corrida de aventura.

\section{Resultados e Discussão}

Vinte e quatro atletas (18 homens e 6 mulheres, $38 \pm 6$ anos, 74,2 $\pm 11,2 \mathrm{~kg}$ de massa corporal, $171 \pm 6 \mathrm{~cm}$ de estatura e 3.222,7 $\pm 1.031,8$ METs no Questionário Internacional de Atividade Física - IPAQ) participantes da $2^{\mathrm{a}}$ e $4^{\mathrm{a}}$ etapas do Circuito Haka Race de Corrida de Aventura - $2015 \mathrm{em}$ duplas foram voluntários nesse estudo (CEP n. 711.659/2014; 980.621/2015). A $2^{2}$ etapa ocorreu na cidade de Jacareí/SP e contemplou um total de $44,5 \mathrm{~km}$. Nesta etapa a prova iniciou com mountain bike, seguido de um trajeto de trekking. Na sequência, a dupla se separou, sendo que enquanto um atleta da dupla realizava trekking ou outro seguia 0 percurso com a canoagem simultaneamente. Finalizado esse trecho, o atleta que realizou trekking passou para canoagem e o seu dupla seguiu de trekking e realizou uma técnica vertical. Em seguida, a dupla se reencontrou e seguiu por um trecho misto de trekking com mountain bike e concluiu a prova por por um percurso de mountain bike. Já na $4^{\underline{a}}$ etapa, realizada em Passa Quatro/MG com $37,1 \mathrm{~km}$, a prova foi composta por uma sequência de mountain bike, trekking com técnica vertical, water trekking com trekking e mountain bike. Análises das distâncias e dos tempos parciais e finais das equipes foram feitas a partir dos relatórios oficiais da organização da prova. Por meio destes dados foram calculadas as velocidades de mountain mountain bike e trekking e a velocidade de provas das equipes, considerando-as como índices de desempenho. Correlação de Pearson foi empregada e o nível de significância estabelecido em $\mathrm{P}<0.05$ (Statistic 7.0). Observamos que a velocidade de prova das equipes na etapa de Jacareí foi correlacionada significativamente $\left(P_{<}\right.$ $0,05)$ com a velocidade do primeiro trecho de trekking $(R=$ $0,80)$ e do último trecho de mountain bike $(R=0,72)$, já na etapa de Passa Quatro foi associada significativamente $(P<0,05)$ com a velocidade do percurso de water trekking com trekking $(\mathrm{R}=0,95)$.

\section{Conclusões}

Concluímos que o desempenho dos atletas nas modalidades de mountain bike e trekking está associado ao desempenho final em competições de corrida de aventura. Além disso, que a contribuição de cada uma dessas modalidades para o desempenho na competição pode ser distinta para diferentes provas disputadas e, possivelmente dependente da ordem e grau de dificuldade do terreno em que são realizadas durante a corrida de aventura.

\section{Agradecimentos}

Nossos agradecimentos ao Laboratório de Fisiologia Aplicada ao Esporte (LAFAE)-FCA-Unicamp, aos voluntários, ao Leonardo Barbosa (diretor do Haka Race), ao Fábio Carlini e ao Fabio Maia pela contribuição nesse estudo. Este estudo foi financiado pelo $\mathrm{PIBIC/CNPq/UNICAMP}$ e pelo FAEPEX-PRP-UNICAMP $(1152 / 14)$.

\footnotetext{
Figueiredo, P., Marques, E.A.; Lepers, R Changes in Contributions of Swim, Cycle, and Run Performances on Overall Triathlon Performance over a 26-year period. Journal of Strength and Conditioning Research. (in press) 2016.

Junior, M.M.; Castro, F.S.; Vaz, M.A. Relevância do trekking e do mountain bike para o desempenho em Corrida de Aventura. Revista de Educação Física. (142): 5-11. 2008.
} 